\title{
A Study on the Hybrid Start-up Intention by Using the Model of Goal-Directed Behavior (MGB)
}

\author{
Kyung-Ho Yun ${ }^{1}$, Jung-Wan Hong ${ }^{2} \&$ Yen-Yoo You ${ }^{2}$ \\ ${ }^{1}$ Department of Knowledge Service and Consulting, Hansung University, Seoul, South Korea \\ ${ }^{2}$ Division of Smart Management Engineering, Hansung University, Seoul, South Korea \\ Correspondence: Jung-Wan Hong, Professor, Division of Smart Management Engineering, Hansung University, \\ Seoul, South Korea. Tel: 82-10-7587-4392. E-mail: jwhong@ hansung.ac.kr
}

Received: April 9, 2020

Accepted: May 9, 2020

Online Published: May 23, 2020

doi:10.5430/rwe.v11n2p22

URL: https://doi.org/10.5430/rwe.v11n2p22

\begin{abstract}
Background/Objectives: The hybrid start-up is when a worker keeps his or her job and at the same time starts a business. This study is intended to analyze the impact of factors on the hybrid start-up desire and the hybrid start-up intention by applying the Model of Goal-directed Behavior (MGB).

Methods/Statistical analysis: After establishing a research model that combines the hybrid start-up with the MGB, a survey was conducted on office workers for one month from December 2019. Of the collected samples, 101 copies suitable for the study were subjected to a statistical analysis such as evaluation of the measurement model and the structural model by using PLS-SEM with SmartPLS 3.0.

Findings: The results of empirical analysis showed that attitude, positive anticipated emotion and negative anticipated emotion among the five factors presented in the MGB had a statistically positive effect on the hybrid start-up desire. However, subjective norm and perceived behavioral control didn't have a statistically significant effect on the hybrid start-up desire. Like other models of goal-directed behavior, the hybrid start-up desire was found to be the most important in the hybrid start-up intention. And, it was also found that there was a mediation effect between the above three factors (attitude, positive anticipated emotion, negative anticipated emotion) and the intention of starting a business. In this study, it suggests that a start-up consulting should be made to take into account the objective aspects in the future, given that the hybrid start-up desire and intention are increased by subjective attitudes and anticipated emotions while not ready for start-up. And considering that most office workers are not ready to start their own businesses and want to consult on their own businesses, there is a need to expand the hybrid start-up consulting.

Improvements/Applications: Future researches need to study the effectiveness of a start-up consulting through whether there is any change in the behavioral model before and after a start-up consulting. Research on hybrid start-ups will help improve government policies and systems that encourage office workers to start their own hybrid businesses.
\end{abstract}

Keywords: behavioral model, start-up, hybrid start-up, preliminary start-up, start-up intention, start-up consulting

\section{Introduction}

The hybrid start-up refers to starting a business at the same time while remaining as a basic wage earner at work (Kim and Yang, 2018). Hybrid start-ups are developing in the form of universal start-ups in advanced countries such as Europe, and in South Korea, some interest in hybrid start-ups using spare time is expected to increase as workers have more free time due to the increase of irregular workers and the implementation of the 52-hour workweek (Kim and Yang, 2018). Hybrid start-ups are an important form of start-ups, with about $18.9 \%$ of all start-ups having both a job and a leave of absence in South Korea, according to a survey of start-up companies released by Korea Institute of Start-up and Entrepreneurship Development in April 2019. In order to increase successful start-ups through pilot application of start-up ideas and reduce unemployment resulting from failure of start-ups, it will be necessary for small and medium enterprises in South Korea to promote hybrid start-ups.

The purpose of this study is to present the necessity and direction of hybrid start-ups as a means of economic activities to solve the problem of irregular workers and unemployment, and to extend the life span of human beings through the study of behavioral models on the intention of a hybrid start-up in South Korea. 


\section{Materials and Methods}

\subsection{Theoretical Background}

\subsubsection{Trends of the Hybrid Start-up}

The study on hybrid start-ups began in earnest in 2010 by several researchers, which showed that the lower the job satisfaction level of office workers, the higher the intention of hybrid start-ups, and the greater the impact of thinking about the fairness of wages than the suitability of working hours (Kim and Yang, 2018). In addition, studies have confirmed that the hybrid entrepreneurship is important as a distinct process of entrepreneurial entry that can enable learning and be useful to competent individuals who lack entrepreneurial experience, and that hybrid start-ups survive longer than full-time start-ups (Raffiee and Feng, 2014; Folta et al., 2010).

Wage earners who intend to start hybrid start-ups can try to start businesses using their own hobbies and specialties through a subsidiary duty or leave of absence, and start-up entrepreneurs who are expected to fail or not have business skills can return to or maintain their own wage status even if they give up their start-ups, thereby reducing social problems and the risk of living.

\subsubsection{Behavioral Models}

The intention of starting a business is defined as the desire of the founder to own or start a business. In the preceding studies, the intention of starting a business was mainly studied as a dependent variable (Chung et al., 2018). In addition, the intention of start-up was ultimately used as a variable to predict and explain start-up behavior in various fields, which gradually developed into the Theory of Reasoned Action (TRA) that attitudes and subjective norms affect behavior intention, the Theory of Planned Behavior (TPB) with the addition of perceived behavioral control, and the Model of Goal-directed Behavior (MGB) considering the emotional aspects (desire, anticipated emotions) (Fishbein and Ajzen, 1975; Ajzen, 1991; Perugini and Bagozzi, 2001). Recently, researchers have expanded their behavioral models according to their fields of study.

First, TRA said that under volitional control, two factors, an individual's attitudes toward behavior and subjective norms, affect behavior intention, and that behavior intention affects actual behavior (Fishbein and Ajzen, 1975). Second, TPB was proposed to explain not only the willful but also the non-willful behavior of the individual, which further presented perceived behavioral control in attitudes and subjective norms that affect behavior intention, thereby increasing the ability to account for behavior intention (Ajzen, 1991). Third, MGB is a theory developed through TRA and TPB by adding variables to increase explanatory power, adding a variable called desire as a prior variable of behavior intention and adding positive anticipated emotion, negative anticipated emotion, frequency of past behavior and recency of past behavior to reflect emotional factors and the influence of past behavior (Perugini and Bagozzi, 2001).

\subsection{Research Model}

The research model of this study was set up as shown in Figure 1 to analyze the effect on the intention of starting a hybrid business in order to boost hybrid start-ups while office workers are at work. Through this model, we wanted to analyze the effects of the five factors (attitude, subjective norm, positive anticipated emotion, negative anticipated emotion, and perceived behavioral control) toward hybrid start-up presented in the goal-directed behavioral theory on the hybrid start-up desire and the effect of hybrid start-up desire on hybrid start-up intention (Perugini and Bagozzi, 2001).

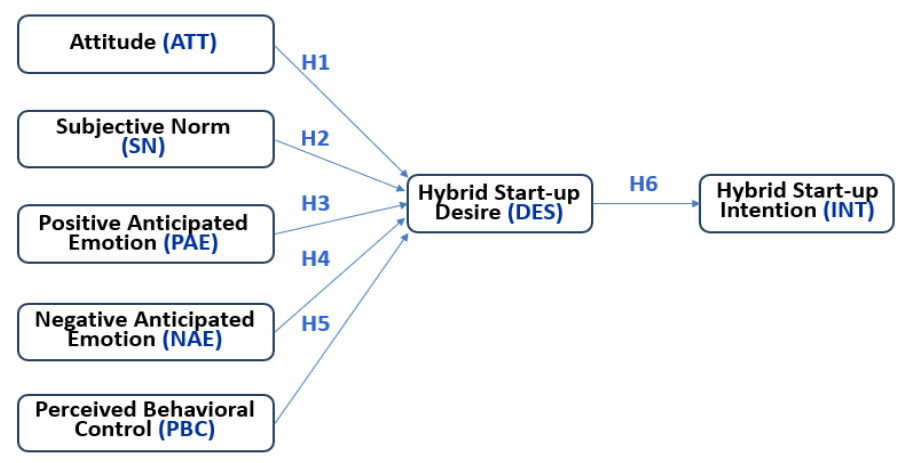

Figure 1. Research model 


\subsection{Research Hypothesis}

Various prior studies have demonstrated that the behavioral model is the right model to predict behavior intention by analyzing the impact of attitude, subjective norm, positive anticipated emotion, negative anticipated emotion, and perceived behavioral control on the start-up desire and intention in various fields.

In cases where the Theory of Planned Behavior (TPB) was applied through 519 samples from two countries, Spain and Taiwan, personal attitude and perceived behavioral control were found to have no statistically significant positive effect on the intention to start a business, but subjective norm did not have a statistically significant positive effect on the intention of a start-up, but indirectly through what is called 'subjective norm $\rightarrow$ personal attitude $\rightarrow$ entrepreneurial intention' and 'subjective norm $\rightarrow$ perceived behavioral control $\rightarrow$ entrepreneurial intention' (Liñán and Chen, 2009).

It raised the question that past researches on TPB was conducted in most Western countries and analyzed TPB through 1,074 samples from six different countries: Germany, India, Iran, Poland, Spain and The Netherlands. The study found that in all six countries, attitude and perceived behavioral control had a statistically significant positive impact on start-up intention, but the subjective norm differed from country to country (Moriano et al., 2012) (Malimi, 2017); (Manaf and Ibrahim, 2017).

There has also been a study that applied the Model of Goal-directed Behavior (MGB) in studying contribution behavior in virtual communities. In this study, desire $(0.63, \mathrm{p}<0.001)$ was shown to have statistically significant and greatest positive effect on intention, and social identity $(0.32, \mathrm{p}<0.001)$, group norms $(0.26, \mathrm{p}<0.001)$, perceived behavioral control $(0.26, \mathrm{p}<0.001)$, anticipated emotions $(0.17, \mathrm{p}<0.01)$, and attitude toward contribution $(0.07, \mathrm{p}<0.05)$ had statistically significant positive effects on desire, but subjective norm was not statistically significant (Tsai and Bagozzi, 2014).

A study on the behavior of visitors to a mixed resort casino found that factors affecting their desire to visit a casino were in the order of negative anticipated emotion, prior knowledge of casinos, positive anticipated emotion, subjective norm, and frequency of past actions. Factors affecting the behavior of visiting complex resorts were shown in the order of desire, prior knowledge of casinos and frequency of past actions. Meanwhile, perceived behavioral control was found to have no effect on both desire and behavior intention, and the attitude toward visiting behavior of complex resort casinos was also analyzed to have no statistically significant effect on desire (Song and Lee, 2010).

Prediction of wine-purchase intention using an extended MGB showed that factors affecting wine-purchasing desire were attitude, subjective norm, and frequency of past behavior, while factors affecting wine-purchasing behavior intention were shown to be desire, frequency of past behavior, but perceived behavioral control didn't affect desire and behavior intention (Ko et al., 2014).

While attitude, positive anticipated emotion, negative anticipated emotion, and perceived behavioral control affected desire in internet purchasing behavior with MGB, subjective norm have not (Park, 2011). In the study on the intention of starting out a restaurant, attitude, subjective norm, and perceived behavioral control had a positive effect on desire and desire had a positive effect on the intention of starting out a restaurant (Kim et al., 2019).

In the study of consumer boycott intentions, negative anticipated emotion, attitude, and perceived behavioral control had positive effects on desire, and desire had a positive effect on consumer boycott intentions, but positive anticipated emotion and subjective norms did not affect desire (Zhang et al., 2017).

In the analysis of religious tourist behavior and behavioral structure, positive anticipated emotion, negative anticipated emotion, and attitudes influenced desire except subjective norm, and perceived behavioral control had a rather low positive effect, and desire had a very large positive effect on religious tourist behavior intention (Yang et al., 2018).

Finally, in the study of the influence factors on the behavior of Chinese tourism, except for negative anticipated emotion, all other factors had statistically significant positive effects on the desire for action, and the desire for action had a very large positive effect on the behavior of the tourism (Yang and Cho, 2015).

However, in this study, if an office worker does a hybrid start-up, subjective norm are also expected to have a positive effect on the hybrid start-up desire. Therefore, the five pre-requisites presented in MGB were all expected to have positive effects on the hybrid start-up desire and the hybrid start-up intention, and the following research hypotheses were established:

< The hypotheses of this study>

H1: Attitude toward hybrid start-up will have a positive effect on hybrid start-up desire.

H2: Subjective norm toward hybrid start-up will have a positive effect on hybrid start-up desire. 
H3: Positive anticipated emotion toward hybrid start-up will have a positive effect on hybrid start-up desire.

H4: Negative anticipated emotion toward hybrid start-up will have a positive effect on hybrid start-up desire.

H5: Perceived behavioral control toward hybrid start-up will have a positive effect on hybrid start-up desire.

H6: Hybrid start-up desire will have a positive effect on hybrid start-up intention.

\subsection{Research Methods}

\subsubsection{Sample Selection}

Considering that the retirement age in South Korea is the majority of 60 years old, the survey was conducted on workers in their 30s to 50s by applying the Judgment Sampling. After a total of 105 questionnaires were collected for about a month from December 2019, 101 copies were confirmed as valid samples, except for 4 copies that were conducted by non-employees.

Since 101 valid samples are larger than 92 minimum samples by the G*Power program under the conditions of effect size $\mathrm{f}^{2}=0.15, \alpha$ err prob $=0.05$, and power $(1-\beta$ err prob $)=0.8$, the sample size is deemed suitable for statistical analysis (Hair et al., 2017).

\subsubsection{Operational Definition and Measurement of Variables}

Based on the model of goal-directed behavior (MGB) and prior studies, the latent variables of this study are defined as follows.

The attitude (ATT) toward hybrid start-ups was measured by a subjective assessment by individuals and defined whether it would be useful, wise or necessary to start a hybrid start-up. Subjective norm (SN) defined whether my neighbors, including my family, friends and colleagues, approve, understand, or recommend my hybrid start-up. Positive anticipated emotion (PAE) was defined as happiness, pride, and confidence when it was possible to start a hybrid business. Negative anticipated emotion (NAE) was defined as anxiety, shame, and sadness in the case of not being able to start a hybrid business. Perceived behavioral control (PBC) was defined as controllability, time investment, and difficulty for hybrid start-ups. Hybrid start-up desire (DES) was defined by hope, success, and passion for hybrid start-ups. Hybrid start-up intention (INT) was defined as the practicability of hybrid start-ups and the possibility of recommendation to those around them.

The measured variables are comprised of a total of 21 survey items, except for the demographic survey as shown in Table 1, and the measurement method was based on the Likert 7-point scale.

Table 1. Composition of survey

\begin{tabular}{|c|c|c|c|}
\hline $\begin{array}{c}\text { Latent } \\
\text { variables }\end{array}$ & & Measured variables (the content of survey) & $\begin{array}{l}\text { Preceding } \\
\text { studies }\end{array}$ \\
\hline \multirow{3}{*}{$\begin{array}{l}\text { Attitude } \\
\text { (ATT) }\end{array}$} & ATT1 & It is useful behavior for me to start a Hybrid business. & \multirow{13}{*}{$\begin{array}{c}\text { (Liñán } \\
\text { and Chen, } \\
\text { 2009; } \\
\text { Moriano } \\
\text { et al., } \\
\text { 2012; Tsai } \\
\text { and } \\
\text { Bagozzi, } \\
\text { 2014; } \\
\text { Song and } \\
\text { Lee, 2010; } \\
\text { Ko et al., } \\
\text { 2014 } \\
\text { Park, } \\
\text { 2011; } \\
\text { Kim et al., } \\
\text { 2019; } \\
\text { Zhang et }\end{array}$} \\
\hline & ATT2 & It is wise behavior for me to start a Hybrid business. & \\
\hline & ATT3 & It is necessary behavior for me to start a Hybrid business. & \\
\hline \multirow{3}{*}{$\begin{array}{l}\text { Subjective } \\
\text { Norm } \\
(\mathrm{SN})\end{array}$} & SN1 & $\begin{array}{l}\text { People around me (family, friends, colleagues, etc.) will approve of } \\
\text { my starting a Hybrid business. }\end{array}$ & \\
\hline & SN2 & $\begin{array}{l}\text { People around me (family, friends, colleagues, etc.) will understand } \\
\text { my starting a Hybrid business }\end{array}$ & \\
\hline & $\mathrm{SN} 3$ & $\begin{array}{l}\text { People around me (family, friends, colleagues, etc.) will recommend } \\
\text { my starting a Hybrid business }\end{array}$ & \\
\hline \multirow{3}{*}{$\begin{array}{c}\text { Positive } \\
\text { Anticipated } \\
\text { Emotion (PAE) }\end{array}$} & PAE1 & If I could start a Hybrid business, I would be happy & \\
\hline & PAE2 & If I could start a Hybrid business, I would be proud & \\
\hline & PAE3 & If I could start a Hybrid business, I would be full of confidence & \\
\hline \multirow{3}{*}{$\begin{array}{c}\text { Negative } \\
\text { Anticipated } \\
\text { Emotion (NAE) }\end{array}$} & NAE1 & If I could not start a Hybrid business, I would be worried & \\
\hline & NAE2 & If I could not start a Hybrid business, I would be ashamed & \\
\hline & NAE3 & If I could not start a Hybrid business, I would be sad & \\
\hline Perceived & PBC1 & I can start a Hybrid business anytime I want & \\
\hline
\end{tabular}




\begin{tabular}{|c|c|c|c|}
\hline \multirow{2}{*}{$\begin{array}{c}\text { Behavioral } \\
\text { Control (PBC) }\end{array}$} & $\mathrm{PBC} 2$ & I have enough time to start a Hybrid business & \multirow{8}{*}{$\begin{array}{c}\text { al., 2017; } \\
\text { Yang et } \\
\text { al., 2018; } \\
\text { Yang and } \\
\text { Cho, } \\
\text { 2015) }\end{array}$} \\
\hline & PBC3 & It is not difficult for me to start a Hybrid business & \\
\hline \multirow{3}{*}{$\begin{array}{l}\text { Hybrid Start-up } \\
\text { Desire } \\
\text { (DES) }\end{array}$} & DES1 & I hope to start a Hybrid business in the near future & \\
\hline & DES2 & I want to succeed through Hybrid Start-up & \\
\hline & DES3 & My will to start a Hybrid business is passionate & \\
\hline \multirow{3}{*}{$\begin{array}{l}\text { Hybrid Start-up } \\
\text { Intention } \\
\text { (INT) }\end{array}$} & INT1 & I will start a Hybrid business if I have a good chance in the future & \\
\hline & INT2 & I will try to start a Hybrid business before I retire & \\
\hline & INT3 & I will strongly recommend the Hybrid start-up to people around me & \\
\hline
\end{tabular}

\subsubsection{Statistical Analysis Method}

In this study, we used SmartPLS 3.0, one of the statistical analysis programs, which evaluated the reflective measurement model with internal consistency reliability, convergent validity, and discriminant validity, and evaluated the structural model with collinearity assessment, coefficient of determination $\left(\mathrm{R}^{2}\right.$ value), effect size $\left(\mathrm{f}^{2}\right.$ value), predictive relevance $\left(Q^{2}\right.$ value), and significance of path coefficients (Hair et al., 2017; Shin, 2018) .

\section{Results and Discussion}

\subsection{Sample Characteristics}

The results of the demographic frequency analysis are shown in Table 2 . The ratio of men and women was $73.3 \%$ and $26.7 \%$, respectively, more than double that of men. Among the age groups, $71.3 \%$ were in their $40 \mathrm{~s}$, and $53.5 \%$ were working for more than 10 to less than 19 years.

In addition, about $85.1 \%$ of the office workers said they were not ready to start a business, and about $43.6 \%$ of them interested in starting their own businesses were found to be willing to receive consulting on their start-ups.

Table 2. Characteristics of samples

\begin{tabular}{cccc}
\hline & Categories & Frequencies & \% \\
\hline \multirow{3}{*}{ Gender } & Male & 74 & 73.3 \\
& Female & 27 & 26.7 \\
\cline { 2 - 4 } & Total & 101 & 100.0 \\
\hline \multirow{3}{*}{ Age } & $30 \sim 39$ & 19 & 18.8 \\
(years old) & $40 \sim 49$ & 72 & 71.3 \\
& $50 \sim 59$ & 10 & 9.9 \\
\cline { 2 - 4 } & Total & 319 & 100.0 \\
\cline { 2 - 4 } & Less than 5 & 5 & 5.0 \\
Working period & More than 5 less than 10 & 12 & 11.9 \\
(years) & More than 10 less than 19 & 54 & 53.5 \\
& More than 20 less than 29 & 27 & 26.7 \\
\cline { 2 - 4 } & More than 30 & 3 & 3.0 \\
\cline { 2 - 4 } & Total & 319 & 100.0 \\
\hline \multirow{3}{*}{ Ready to start a business } & Yes & 15 & 14.9 \\
& No & 86 & 85.1 \\
\cline { 2 - 4 } & Total & 101 & 100.0 \\
\hline \multirow{2}{*}{ Willing to receive } & Yes & 44 & 43.6 \\
consulting for start-up & No & 57 & 56.4 \\
\cline { 2 - 4 } & Total & 101 & 100.0 \\
\cline { 2 - 4 } & &
\end{tabular}




\subsection{Evaluation of the Measurement Model: Reliability and Validity}

The research model of this study included reflective potential variables, so it was analyzed whether the reliability and validity of the measured variables were obtained by applying internal consistency reliability, convergent validity and discriminative validity, which are the criteria for evaluation of the reflective measurement model in the PLS-SEM(Partial Least Squares-Structural Equation Modeling) (Hair et al., 2017; Shin, 2018).

\subsubsection{Assessing Results of Internal Consistency Reliability}

Internal consistency reliability through SmartPLS statistical analysis can be summarized as shown in Table 3. As the Cronbach's $\alpha$, rho_A $\left(\rho_{\mathrm{A}}\right)$ and CR values all show the desired acceptance criteria of 0.7 or higher, it is believed that they have secured internal consistency reliability.

Table 3. Summary of internal consistency reliability assessment results

\begin{tabular}{|c|c|c|c|c|}
\hline \multirow{3}{*}{$\begin{array}{c}\text { Latent } \\
\text { variables }\end{array}$} & \multirow{3}{*}{$\begin{array}{c}\text { Measured } \\
\text { variables }\end{array}$} & \multicolumn{3}{|c|}{ Internal consistency reliability } \\
\hline & & Cronbach's $\alpha$ & rho_A $\left(\rho_{A}\right)$ & $\mathbf{C R}$ \\
\hline & & $>0.70$ & $>0.70$ & $>0.70$ \\
\hline \multirow{3}{*}{ ATT } & ATT1 & & & \\
\hline & ATT2 & 0.919 & 0.921 & 0.949 \\
\hline & ATT3 & & & \\
\hline \multirow{3}{*}{ SN } & SN1 & & & \\
\hline & $\mathrm{SN} 2$ & 0.927 & 0.932 & 0.953 \\
\hline & SN3 & & & \\
\hline \multirow{3}{*}{ PAE } & PAE1 & & & \\
\hline & PAE2 & 0.908 & 0.909 & 0.942 \\
\hline & PAE3 & & & \\
\hline \multirow{3}{*}{ NAE } & NAE1 & & & \\
\hline & NAE2 & 0.850 & 0.892 & 0.906 \\
\hline & NAE3 & & & \\
\hline \multirow{3}{*}{$\mathrm{PBC}$} & $\mathrm{PBC} 1$ & & & \\
\hline & $\mathrm{PBC} 2$ & 0.822 & 0.842 & 0.893 \\
\hline & PBC3 & & & \\
\hline \multirow{3}{*}{ DES } & DES1 & & & \\
\hline & DES2 & 0.908 & 0.910 & 0.942 \\
\hline & DES3 & & & \\
\hline \multirow{3}{*}{ INT } & INT1 & & & \\
\hline & INT2 & 0.901 & 0.903 & 0.938 \\
\hline & INT3 & & & \\
\hline
\end{tabular}

Ref: 1) rho_A $\left(\rho_{A}\right)$ : Dijkstra-Henseler's rho_A $\left.\left(\rho_{A}\right), 2\right)$ CR: Composite Reliability, 3)

ATT: Attitude, 4) SN: Subjective Norm, 5) PAE: Positive Anticipated Emotion, 6) NAE: Negative Anticipated Emotion, 7) PBC: Perceived Behavioral Control, 8) DES: Hybrid Start-up Desire, 9) INT: Hybrid Start-up Intention

\subsubsection{Assessing Results of Convergent Validity}

Convergent validity can be summarized as shown in Table 4 . It is believed that outer loading values are 0.7 or higher, and that the indicator reliability and the AVE values are both 0.5 or higher, thus the convergent validity of the latent variables and the reliability of the measured variables are secured. 
Table 4. Summary of convergent validity assessment results

\begin{tabular}{|c|c|c|c|c|}
\hline \multirow{3}{*}{$\begin{array}{c}\text { Latent } \\
\text { variables }\end{array}$} & \multirow{3}{*}{$\begin{array}{c}\text { Measured } \\
\text { variables }\end{array}$} & \multicolumn{3}{|c|}{ Convergent validity } \\
\hline & & Outer loading & Indicator reliability & AVE \\
\hline & & $>0.70$ & $>0.50$ & $>0.50$ \\
\hline \multirow{3}{*}{ ATT } & ATT1 & 0.929 & 0.863 & \multirow{3}{*}{0.861} \\
\hline & ATT2 & 0.925 & 0.856 & \\
\hline & ATT3 & 0.930 & 0.865 & \\
\hline \multirow{3}{*}{ SN } & SN1 & 0.936 & 0.876 & \multirow{3}{*}{0.872} \\
\hline & SN2 & 0.933 & 0.870 & \\
\hline & SN3 & 0.933 & 0.870 & \\
\hline \multirow{3}{*}{ PAE } & PAE1 & 0.907 & 0.823 & \multirow{3}{*}{0.845} \\
\hline & PAE2 & 0.921 & 0.848 & \\
\hline & PAE3 & 0.930 & 0.865 & \\
\hline \multirow{3}{*}{ NAE } & NAE1 & 0.867 & 0.752 & \multirow{3}{*}{0.763} \\
\hline & NAE2 & 0.855 & 0.731 & \\
\hline & NAE3 & 0.899 & 0.808 & \\
\hline \multirow{3}{*}{$\mathrm{PBC}$} & PBC1 & 0.831 & 0.691 & \multirow{3}{*}{0.736} \\
\hline & $\mathrm{PBC} 2$ & 0.878 & 0.771 & \\
\hline & PBC3 & 0.863 & 0.745 & \\
\hline \multirow{3}{*}{ DES } & DES1 & 0.918 & 0.843 & \multirow{3}{*}{0.844} \\
\hline & DES2 & 0.914 & 0.835 & \\
\hline & DES3 & 0.924 & 0.854 & \\
\hline \multirow{3}{*}{ INT } & INT1 & 0.903 & 0.815 & \multirow{3}{*}{0.834} \\
\hline & INT2 & 0.931 & 0.867 & \\
\hline & INT3 & 0.906 & 0.821 & \\
\hline
\end{tabular}

\subsubsection{Assessing Results of Discriminant Validity}

The discriminant validity can be determined by Fornell-Larcker criterion, cross-loadings analysis and HTMT (heterotrait-monotrait ratio) as follows. In the case of Fornell-Larcker criterion, the AVE square root of each latent variable is greater than the highest correlation among the latent variables in Table 5. In the case of cross-loadings analysis, the outer loading values shown in Table 4 exceed the cross loading values (ATT: 0.275 0.756, SN: 0.255 0.661, PAE: 0.194 0.706, NAE: 0.071 0.417, PBC: 0.210 0.535, DES: 0.294 0.852, INT: 0.26 0.28). Finally, the values of HTMT are all less than 0.90 except for 0.947 between INT and DES, but the results of the confidence interval estimation method for HTMT values (Table 6) do not contain 1 within the confidence interval, so the discriminant validity between the latent variables is determined to be obtained.

Table 5. Discriminant validity by Fornell-Larcker criterion

\begin{tabular}{cccccccc}
\hline & ATT & DES & INT & NAE & PAE & PBC & SN \\
\hline ATT & $\mathbf{0 . 9 2 8}$ & & & & & & \\
DES & 0.764 & $\mathbf{0 . 9 1 9}$ & & & & & \\
INT & 0.768 & 0.860 & $\mathbf{0 . 9 1 3}$ & & & & \\
NAE & 0.374 & 0.410 & 0.338 & $\mathbf{0 . 8 7 4}$ & & & \\
PAE & 0.746 & 0.678 & 0.675 & 0.239 & $\mathbf{0 . 9 1 9}$ & & \\
PBC & 0.440 & 0.447 & 0.420 & 0.373 & 0.409 & $\mathbf{0 . 8 5 8}$ & \\
SN & 0.647 & 0.576 & 0.628 & 0.360 & 0.555 & 0.493 & $\mathbf{0 . 9 3 4}$ \\
\hline
\end{tabular}


Table 6. Discriminant validity by HTMT criterion

\begin{tabular}{|c|c|c|c|c|c|}
\hline \multirow{2}{*}{ Path } & \multirow{2}{*}{ HTMT } & \multirow{2}{*}{$\begin{array}{c}\text { Sample } \\
\text { mean }\end{array}$} & \multirow{2}{*}{ Bias } & \multicolumn{2}{|c|}{ 95\% Confidence interval } \\
\hline & & & & $2.5 \%$ & $97.5 \%$ \\
\hline $\mathrm{DES} \rightarrow \mathrm{ATT}$ & 0.834 & 0.834 & -0.001 & 0.753 & 0.906 \\
\hline INT $\rightarrow$ ATT & 0.843 & 0.843 & 0.000 & 0.748 & 0.914 \\
\hline $\mathrm{INT} \rightarrow \mathrm{DES}$ & 0.947 & 0.947 & 0.001 & 0.885 & 0.996 \\
\hline $\mathrm{NAE} \rightarrow \mathrm{ATT}$ & 0.402 & 0.402 & 0.000 & 0.217 & 0.565 \\
\hline $\mathrm{NAE} \rightarrow \mathrm{ATT}$ & 0.441 & 0.438 & -0.003 & 0.232 & 0.625 \\
\hline $\mathrm{NAE} \rightarrow \mathrm{ATT}$ & 0.360 & 0.360 & 0.000 & 0.174 & 0.549 \\
\hline $\mathrm{PAE} \rightarrow \mathrm{ATT}$ & 0.815 & 0.816 & 0.001 & 0.723 & 0.889 \\
\hline $\mathrm{PAE} \rightarrow \mathrm{DES}$ & 0.745 & 0.746 & 0.001 & 0.608 & 0.848 \\
\hline $\mathrm{PAE} \rightarrow \mathrm{INT}$ & 0.745 & 0.744 & 0.000 & 0.611 & 0.847 \\
\hline $\mathrm{PAE} \rightarrow \mathrm{NAE}$ & 0.243 & 0.256 & 0.013 & 0.114 & 0.416 \\
\hline $\mathrm{PBC} \rightarrow \mathrm{ATT}$ & 0.493 & 0.492 & -0.002 & 0.285 & 0.659 \\
\hline $\mathrm{PBC} \rightarrow \mathrm{DES}$ & 0.507 & 0.507 & 0.000 & 0.279 & 0.699 \\
\hline $\mathrm{PBC} \rightarrow \mathrm{INT}$ & 0.477 & 0.477 & 0.000 & 0.261 & 0.669 \\
\hline $\mathrm{PBC} \rightarrow \mathrm{NAE}$ & 0.426 & 0.425 & -0.001 & 0.210 & 0.654 \\
\hline $\mathrm{PBC} \rightarrow \mathrm{PAE}$ & 0.469 & 0.465 & -0.004 & 0.280 & 0.634 \\
\hline $\mathrm{SN} \rightarrow \mathrm{ATT}$ & 0.698 & 0.696 & -0.002 & 0.536 & 0.815 \\
\hline $\mathrm{SN} \rightarrow \mathrm{DES}$ & 0.624 & 0.621 & -0.003 & 0.454 & 0.758 \\
\hline $\mathrm{SN} \rightarrow \mathrm{INT}$ & 0.686 & 0.683 & -0.004 & 0.520 & 0.812 \\
\hline $\mathrm{SN} \rightarrow \mathrm{NAE}$ & 0.399 & 0.393 & -0.006 & 0.201 & 0.586 \\
\hline $\mathrm{SN} \rightarrow \mathrm{PAE}$ & 0.603 & 0.600 & -0.002 & 0.451 & 0.724 \\
\hline $\mathrm{SN} \rightarrow \mathrm{PBC}$ & 0.548 & 0.544 & -0.003 & 0.343 & 0.705 \\
\hline
\end{tabular}

Therefore, if we sum up the results of the evaluation of the reflective measurement model, it is deemed that individual measured variables and latent variables of the measurement model have secured reliability and validity since all the evaluation criteria are met.

\subsection{Evaluation of the Structural Model and Hypothesis Testing}

The evaluation of the structural model can finally confirm the research model of this study and confirm that the structural model is an appropriate model. The hypotheses presented in this study can be verified if the above structural model is evaluated to be suitable (Hair et al., 2017; Shin, 2018).

\subsubsection{Evaluation of the Structural Model}

In PLS-SEM, collinearity assessment, coefficient of determination $\left(\mathrm{R}^{2}\right.$ value), effect size ( $\mathrm{f}^{2}$ value), predictive relevance $\left(\mathrm{Q}^{2}\right.$ value) should be reviewed for the evaluation of the structural model. The results of performing Algorithm and bootstrapping with SmartPLS, a statistical analysis program, are shown in Figure 2 and Figure 3. In Figure 2, the number on the arrow is a regression coefficient standardized with outer loading value or path coefficient value, and the number shown in the circle is an adjusted $\mathrm{R}^{2}$. In Figure 3, the number on the arrow indicates the $t$ value (Mangaratua, 2019); (Mbogela, 2019). 


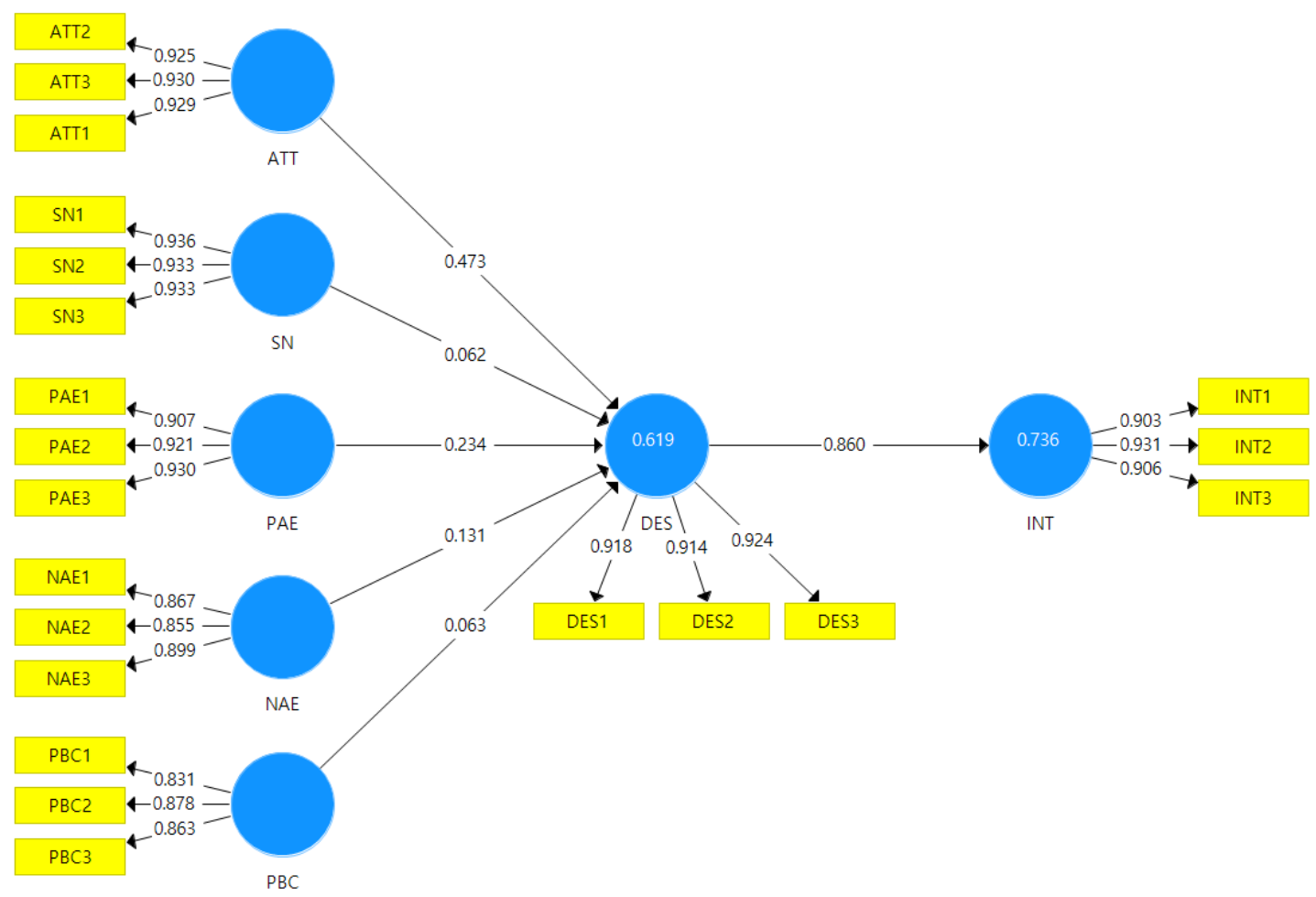

Figure 2. Results of performing PLS-SEM Algorithm (adjusted $\mathrm{R}^{2}$ )

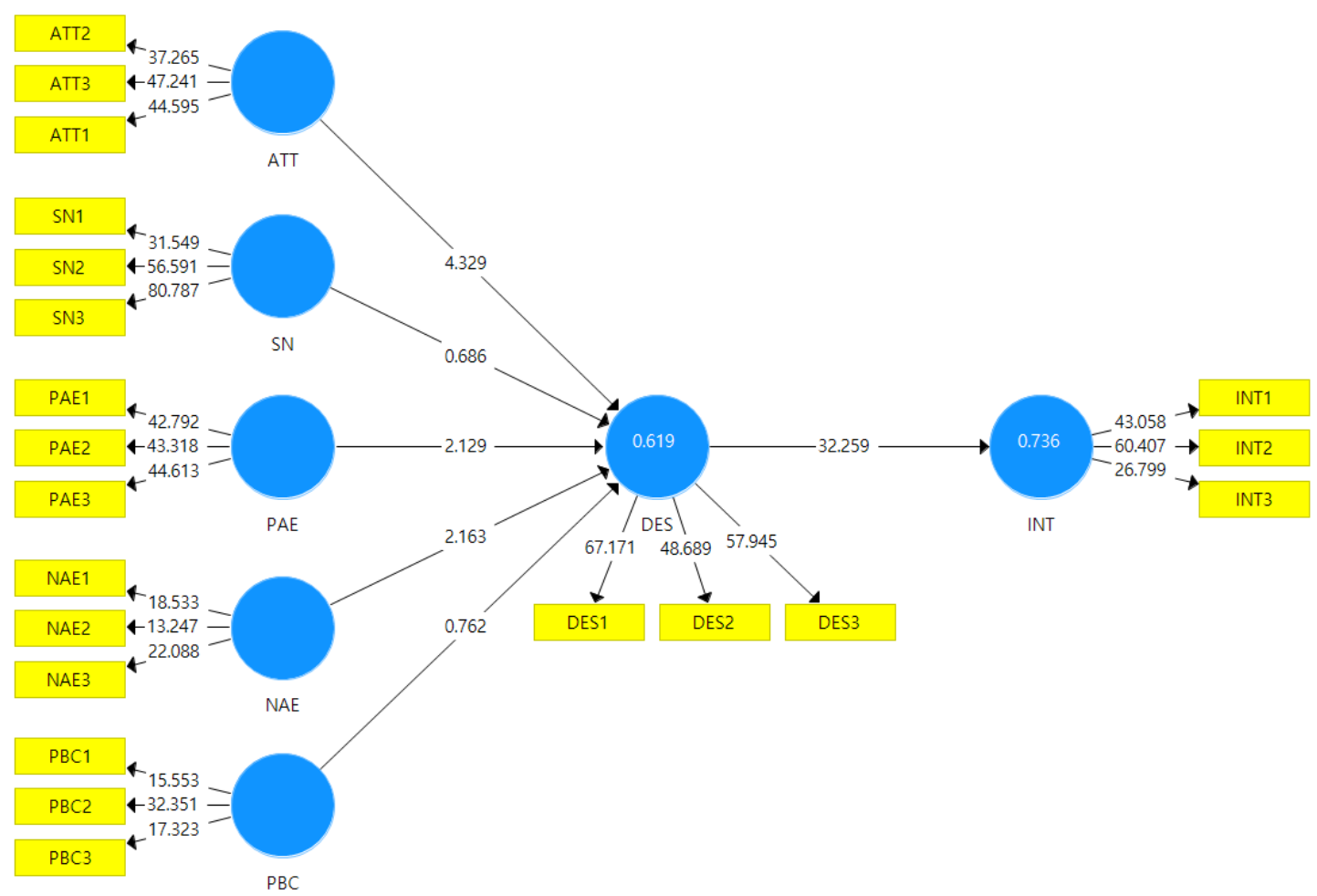

Figure 3. Results of performing PLS-SEM Bootstrapping (adjusted $R^{2}$ ) 
The assessing results of the collinearity assessment among the latent variables are shown in Table 7, and the inner VIF values are all less than 5 and there is no multicollinearity among the latent variables. In addition, as shown in Figure 2 and Table 8 , the adjusted $\mathrm{R}^{2}$ of the endogenous latent variables DES (0.619) and INT (0.736) shows an predictive power of more than 0.50 (moderate value) and above.

Table 7. Assessing results of the collinearity assessment

\begin{tabular}{|c|c|c|c|c|c|c|c|}
\hline & $\overline{\text { ATT }}$ & DES & INT & NAE & PAE & PBC & SN \\
\hline ATT & & 2.873 & & & & & \\
\hline DES & & & 1.000 & & & & \\
\hline INT & & & & & & & \\
\hline NAE & & 1.269 & & & & & \\
\hline PAE & & 2.353 & & & & & \\
\hline PBC & & 1.452 & & & & & \\
\hline SN & & 1.943 & & & & & \\
\hline
\end{tabular}

Table 8. Assessing results of the coefficient determination $\left(\mathrm{R}^{2}\right)$

\begin{tabular}{ccc}
\hline Endogenous latent variable & $\mathbf{R}^{2}$ & Adjusted $\mathbf{R}^{2}$ \\
\hline DES & 0.638 & 0.619 \\
INT & 0.739 & 0.736 \\
\hline
\end{tabular}

For the effect sizes shown in Table 9, the degree to which NAE and PAE contribute to $\mathrm{R}^{2}$ of the endogenous latent variable DES is 0.038 and 0.064 respectively, showing a small degree of effect size $\left(f^{2}=0.02\right)$ and ATT is 0.215 , showing moderate effect size $\left(f^{2}=0.15\right)$. However, $\mathrm{PBC}$ and $\mathrm{SN}$ were found to contribute little to the $\mathrm{R}^{2}$ of the DES, with $0.008,0.005$, respectively.

Table 9. Assessing results of the effect size $\left(\mathrm{f}^{2}\right)$

\begin{tabular}{|c|c|c|c|c|c|c|c|}
\hline & ATT & DES & INT & NAE & PAE & PBC & SN \\
\hline ATT & & 0.215 & & & & & \\
\hline DES & & & 2.829 & & & & \\
\hline INT & & & & & & & \\
\hline NAE & & 0.038 & & & & & \\
\hline PAE & & 0.064 & & & & & \\
\hline PBC & & 0.008 & & & & & \\
\hline SN & & 0.005 & & & & & \\
\hline
\end{tabular}

The evaluation of predictive relevance in Table 10 shows that the $Q^{2}$ of the endogenous latent variables (DES, INT) is all greater than 0 , so the structural model is judged to have predictive relevance.

Table 10. Assessing results of the predictive relevance $\left(Q^{2}\right)$

\begin{tabular}{cc}
\hline Endogenous latent variable & $\mathbf{Q}^{\mathbf{2}}$ \\
\hline DES & 0.518 \\
INT & 0.605 \\
\hline
\end{tabular}

\subsubsection{Hypothesis Testing}

The significance and relevance of the path coefficients shown in the structural model in Figure 2 are shown in Table 11. 
In Table 11, the $\mathrm{t}$ values and $\mathrm{p}$ values show that hypothesis 2 and hypothesis 5 have been rejected, and that the remaining hypotheses 1 , hypothesis 3, hypothesis 4 and hypothesis 6 have been accepted. Attitudes $(0.473)$ had the greatest statistically significant positive effect on the hybrid start-up desire, followed by positive anticipated emotion $(0.234)$ and negative anticipated emotion $(0.131)$. And, we were able to confirm that the hybrid start-up desire $(0.860)$ had a statistically significant positive effect on the hybrid start-up intention.

Table 11. Results of significance and relevance of path coefficients (Hypothesis Testing)

\begin{tabular}{|c|c|c|c|c|c|c|}
\hline \multicolumn{2}{|c|}{ Hypothesis / Path } & \multirow{2}{*}{$\begin{array}{c}\begin{array}{c}\text { Path } \\
\text { coefficient }\end{array} \\
0.473\end{array}$} & \multirow{2}{*}{$\begin{array}{c}\text { t value } \\
4.329\end{array}$} & \multirow{2}{*}{$\begin{array}{c}\text { p value } \\
0.000\end{array}$} & \multirow{2}{*}{$\begin{array}{c}\mathbf{9 5 \%} \\
\text { Confidence interval } \\
{[0.257,0.684]}\end{array}$} & \multirow{2}{*}{$\begin{array}{c}\begin{array}{c}\text { Significant } \\
(\mathbf{p}<\mathbf{0 . 0 5})\end{array} \\
\text { Yes }\end{array}$} \\
\hline H1 & $\mathrm{ATT} \rightarrow \mathrm{DES}$ & & & & & \\
\hline $\mathrm{H} 2$ & $\mathrm{SN} \rightarrow \mathrm{DES}$ & 0.062 & 0.686 & 0.492 & {$[-0.112,0.239]$} & No \\
\hline H3 & $\mathrm{PAE} \rightarrow \mathrm{DES}$ & 0.234 & 2.129 & 0.033 & {$[-0.003,0.428]$} & Yes \\
\hline $\mathrm{H} 4$ & $\mathrm{NAE} \rightarrow \mathrm{DES}$ & 0.131 & 2.163 & 0.031 & {$[0.010,0.246]$} & Yes \\
\hline H5 & $\mathrm{PBC} \rightarrow \mathrm{DES}$ & 0.063 & 0.762 & 0.446 & {$[-0.094,0.231]$} & No \\
\hline H6 & $\mathrm{DES} \rightarrow \mathrm{INT}$ & 0.860 & 32.259 & 0.000 & {$[0.799,0.905]$} & Yes \\
\hline
\end{tabular}

Finally, the results of hypothesis testing are shown in Table 12, with 4 hypotheses accepted and 2 hypotheses rejected. Figure 4 shows the outer loading values between the latent and the measured variables and the path coefficients between the exogenous and endogenous latent variables, and the magnitude of the influence.

Table 12. The results of hypothesis testing

\begin{tabular}{clc}
\hline Hypothesis & \multicolumn{1}{c}{ Hypothesis to be tested } & Results \\
\hline H1 & Attitude toward hybrid start-up will have a positive effect on hybrid start-up desire & Accept \\
\hline H2 & $\begin{array}{l}\text { Subjective norm toward hybrid start-up will have a positive effect on hybrid start-up } \\
\text { desire }\end{array}$ & Reject \\
\hline H3 & $\begin{array}{l}\text { Positive anticipated emotion toward hybrid start-up will have a positive effect on } \\
\text { hybrid start-up desire }\end{array}$ & Accept \\
\hline H4 & $\begin{array}{l}\text { Negative anticipated emotion toward hybrid start-up will have a positive effect on } \\
\text { hybrid start-up desire }\end{array}$ & Accept \\
\hline H5 & $\begin{array}{l}\text { Perceived behavioral control toward hybrid start-up will have a positive effect on } \\
\text { hybrid start-up desire }\end{array}$ & Reject \\
\hline H6 & Hybrid start-up desire will have a positive effect on hybrid start-up intention & Accept \\
\hline
\end{tabular}




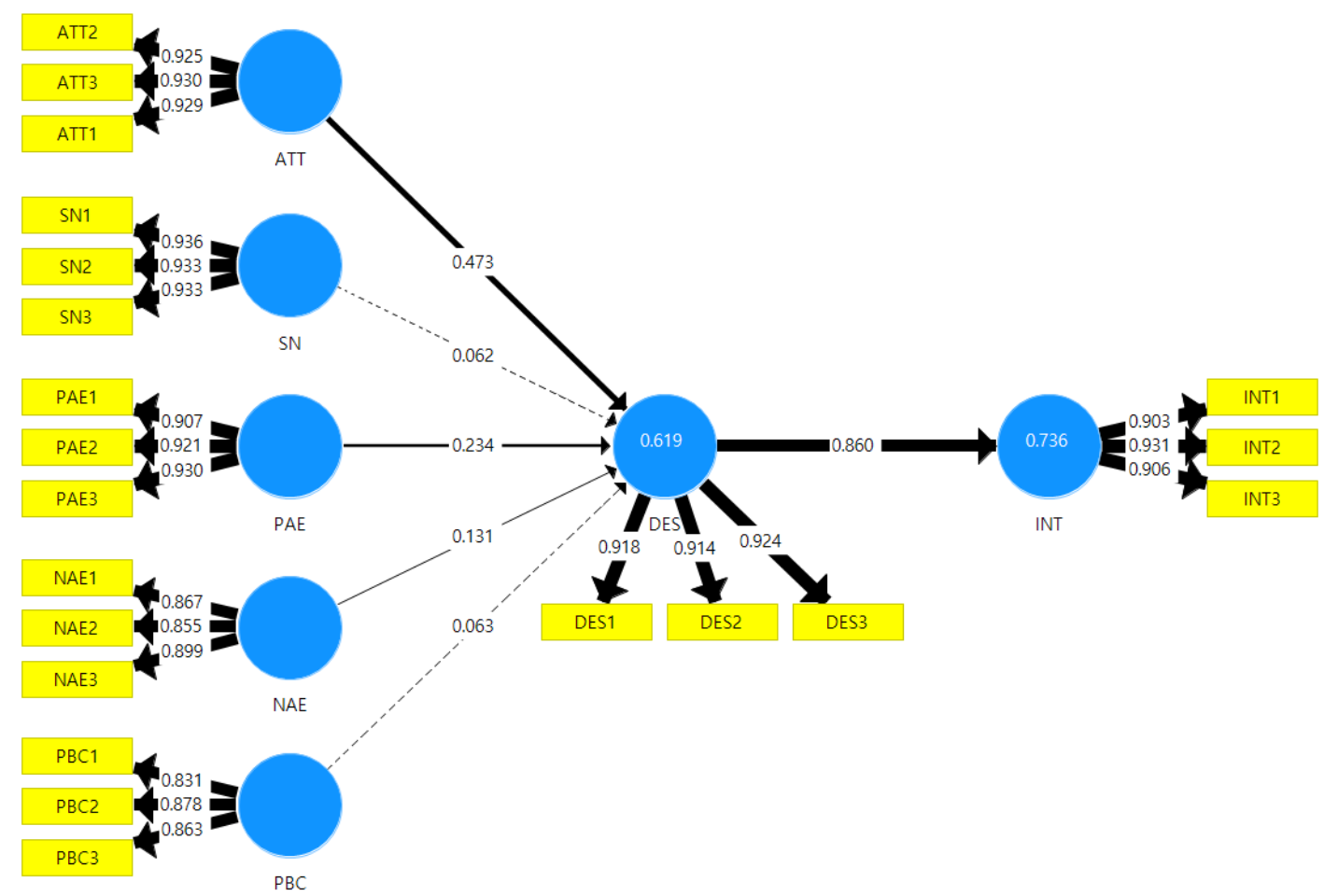

Figure 4. Structural path coefficient analysis

\subsubsection{Mediation Effect Testing}

In addition, the analysis of specific indirect effects verifies the mediation effects as shown in Table 13. Some of the mediation effects among specific indirect paths were ATT $\rightarrow$ DES $\rightarrow$ INT, PAE $\rightarrow$ DES $\rightarrow$ INT, NAE $\rightarrow$ DES $\rightarrow$ INT. We can confirm that the hybrid start-up desire has a mediation effect between three factors (attitude, positive anticipated emotion, negative anticipated emotion) and the hybrid start-up intention.

Table 13. Mediation effect testing by specific indirect effect

\begin{tabular}{cccccc}
\hline Hypothesis $/$ Path & $\begin{array}{c}\text { Path } \\
\text { coefficient }\end{array}$ & $\begin{array}{c}\text { Standard } \\
\text { deviation }\end{array}$ & t value & p value & $\begin{array}{c}\text { Significant } \\
(\mathbf{p}<\mathbf{0 . 0 5})\end{array}$ \\
\hline $\mathrm{ATT} \rightarrow \mathrm{DES} \rightarrow \mathrm{INT}$ & 0.406 & 0.096 & 4.231 & 0.000 & Yes \\
$\mathrm{SN} \rightarrow \mathrm{DES} \rightarrow \mathrm{INT}$ & 0.053 & 0.078 & 0.684 & 0.494 & No \\
$\mathrm{PAE} \rightarrow \mathrm{DES} \rightarrow \mathrm{INT}$ & 0.201 & 0.094 & 2.136 & 0.033 & Yes \\
$\mathrm{NAE} \rightarrow \mathrm{DES} \rightarrow \mathrm{INT}$ & 0.113 & 0.052 & 2.165 & 0.030 & Yes \\
$\mathrm{PBC} \rightarrow \mathrm{DES} \rightarrow \mathrm{INT}$ & 0.054 & 0.071 & 0.763 & 0.445 & No \\
\hline
\end{tabular}

\section{Conclusion}

\subsection{Result Summary and Implication}

As the number of hybrid start-ups actively conducted in advanced countries is expected to increase in South Korea due to 52 hours of work per week and job insecurity caused by the Fourth Industrial Revolution, this research was designed to analyze the impact of the factors on the hybrid start-up desire and intention by applying the Model of Goal-directed Behavior (MGB) to promote the start-up while maintaining the work life. The results of this study could be used for the consulting of hybrid start-ups. The results of this study are summarized as follows.

First, the empirical analysis of this study showed that attitudes, positive and negative anticipated emotions among the five factors presented in MGB have statistically positive effects on the hybrid start-up desire. This means that the 
passion for starting a business is created by a variety of emotions such as stress, anxiety, confidence, and spirit of challenge in working life, and by the mindset that workers normally have as they encounter those around them who have succeeded or failed through business. Second, subjective norm and perceived behavioral control did not have statistically significant effects on the hybrid start-up desire. This means that the passion for starting a business is generated by our subjective will regardless of the opinions of the people around us about the start-up or the behavioral control we normally recognize. Third, like other behavioral models, it turns out that the desire to start a hybrid business is paramount for the intention of starting a hybrid business. Fourth, the desire to start a business has been found to have a mediated effect between the above three factors (attitude, positive anticipated emotion and negative anticipated emotion) and the intention to start a business. This is due to the very large influence of the desire to start a hybrid business.

In addition, about $85 \%$ of office workers surveyed in this study were analyzed that their desire and intention to start hybrid businesses were influenced by subjective attitudes and expected emotions while they were not ready to start businesses. In addition to subjective factors, it is judged that in the future, objective factors should be presented and some start-up consulting should be expanded to ensure successful hybrid start-ups. Given that many office workers hope to receive some hybrid start-up consulting, even though most are not ready to start their own business, various hybrid start-up consulting is likely to enable them to start their own business.

\subsection{Limitation and Future Direction}

This study aims to present the following limitations and further research directions as it attempts to research by simply combining hybrid start-ups with the goal-directed behavioral models presented in advance.

First, it is necessary to study existing behavioral models by adding factors suitable for the hybrid start-up. Given the hybrid start-up, factors corresponding to office workers and those corresponding to start-ups need to be discovered through prior studies and considered in future extended models. Second, although the sample size of this study met the minimum sample size required for PLS-SEM, it is necessary to expand the sample size for various studies. There is a different need for hybrid start-ups among workers in their 20s, 30s and 40s, and while expanding regular workers and job discrimination between men and women are improving, there may be differences in factors regarding hybrid start-ups between regular and non-regular workers and between men and women. Third, further researches need to be done to identify changes in the behavioral model before and after start-up consulting. This could suggest the need for start-up consulting for office workers. Finally, it is necessary to break away from academic research and suggest ways to improve government policies or systems to encourage workers to start a business. In South Korea, hybrid start-ups have yet to be activated due to the prohibition of outside work on large companies and public institutions. It is expected that if hybrid start-ups are activated in the workplace, they will seek to boost weak start-ups in South Korea, such as studying various fields through multiple majors at universities.

\section{Acknowledgment}

This research was financially supported by the Hansung University.

\section{References}

Ajzen, I. (1991). The theory of planned behavior. Organizational Behavior and Human Decision Processes, 50(2), 179-211.

Chung, D. Y., Kim, Y. S., \& Kim, J. H. (2018). The effect of subjective norm on entrepreneurial intention mediated by personal attitude and perceived behavioral control: Focusing on Linan and Chen (2009)'EIM. Korean Business Education Review, 33(1), 183-204.

Fishbein, M., \& Ajzen, I. (1975). Belief, attitude, intention and behaviour: An introduction to theory and research. Reading, MA: Addison-Wesley.

Folta, T. B., Delmar, F., \& Wennberg, K. (2010). Hybrid entrepreneurship. Management Science, 56(2), 253-69.

Hair, Jr J. F., Hult, G. T. M., Ringle, C., \& Sarstedt, M. (2017). A primer on partial least squares structural equation modeling (PLS-SEM) (2nd ed.). Los Angeles: Sage Publications.

Kim, J. H., \& Yang, D. W. (2018). A study on the influence of job satisfaction and entrepreneurship on hybrid entrepreneurial intention: Focusing on the mediating roles of entrepreneurial self-efficacy. The Korea Entrepreneurship Society Conferences, 2018(3), 1-22. Retrieved from http://www.riss.kr/link?id=A106336049

Kim, J. H., Lee, S. B., \& Lee, S. W. (2019). Start-up intention through the integration of self-determination and goal-oriented theory. Journal of Foodservice Management, 22(6), 163-84. Retrieved from 
http://www.riss.kr/link?id=A106528682

Ko, J. Y., Song, H. H., \& Yoo, E. Y. (2014). Predicting wine purchasing Intention using extended model of goal -didrected behavior. The Tourism Sciences Society of Korea, 38(4), 11-36. Retrieved from http://www.riss.kr/link?id=A100006460

Liñán, F., \& Chen, Y. W. (2009). Development and cross-cultural application of a specific instrument to measure entrepreneurial intentions. Entrepreneurship Theory and Practice, 33(3), 593-617.

Malimi, K. (2017). The influence of capital adequacy, profitability, and loan growth on non-performing loans a case of Tanzanian banking sector. International Journal of Economics, Business and Management Studies, 4(1), 38-49.

Manaf, N. A., \& Ibrahim, K. (2017). Poverty reduction for sustainable development: Malaysia's evidence-based solutions. Global Journal of Social Sciences Studies, 3(1), 29-42.

Mangaratua, E. (2019). Profitability behavior of plastic industries in Indonesia. Economics, 6(1), 78-91.

Mbogela, C. (2019). An empirical examination on trade openness and economic growth nexus in Africa. Asian Journal of Economics and Empirical Research, 6(1), 1-15. https://doi.org/10.20448/journal.501.2019.61.1.15

Moriano, J. A., Gorgievski, M., Laguna, M., Stephan, U., \& Zarafshani, K. (2012). A cross-cultural approach to understanding entrepreneurial intention. Journal of Career Development, 39(2), 162-85.

Park, H. R. (2011). Understanding internet purchase behaviour based on model of goal-directed behaviour: Focused on need for cognition. The Korean Journal of Advertising, 22(2), 67-95. Retrieved from http://www.riss.kr/link?id=A82612569

Perugini, M., \& Bagozzi, R. P. (2001). The role of desires and anticipated emotions in goal-directed behaviours: Broadening and deepening the theory of planned behaviour. British Journal of Social Psychology, 40(1), 79-98.

Raffiee, J., \& Feng, J. (2014). Should I quit my day job?: A hybrid path to entrepreneurship. Academy of Management Journal, 57(4), 936-63.

Shin, G. K. (2018). Partial least squares structural equation modeling(PLS-SEM) with SmartPLS 3.0, SPSS, G*Power. Seoul: Chung-Ram. Retrieved from http://www.riss.kr/link?id=M14841412

Song, H. J., \& Lee, C. K. (2010). Predicting behavioral intentions for visitors to integrated resort casino using model of goal-directed behavior. The Korea Academic Society of Tourism and Leisure, 22(5) 341-60. Retrieved from http://www.riss.kr/link?id=A82416347

Tsai, H. T., \& Bagozzi, R. P. (2014). Contribution behavior in virtual communities: Cognitive, emotional, and social influences. Mis Quarterly, 38(1), 143-64.

Yang, E. J., \& Cho, M. H. (2015). A study on the influence factors of behavior intention for chinese cosmetic surgery tourism: Focusing on extended model of goal-directed behavior. Journal of Tourism Science, 39(6), 47-64. https://doi.org/10.17086/JTS.2015.39.5.47.64

Yang, S. T., Lee, S. K., \& Yoo, J. R. (2018). Analysis of the structural relationship between religious tourists' motivation and behavior: Based on the extended MGB. International Journal of Tourism and Hospitality Research, 32(12), 195-211. https://doi.org/10.21298/IJTHR.2018.12.32.12.195

Zhang, M. J., Lee, S. S., \& Ryu, M. H. (2017). A study on influencing factors on consumer boycott intention by applying extended model of goal-directed behavior. Family and Environment Research, 55(6), 675-87. https://doi.org/10.6115/fer.2017.049 